Paulo Bastos Cruz Filho, engenheiro mecânico Paulo Bastos Cruz Filho e administrador industrial. É, atualmente, diretor da Associação Nacional dos Fabricantes de Papel e Celulose - ANFPC, membro da Comissão Permanente de Meio Ambiente e

Uso do Solo da Confederação Nacional da Indústria e presidente da Comissão de Planejamento Urbano da Baixada Santista.

\title{
Controle ambiental em fábricas de papel e celulose
}

\section{Introdução}

A atividade industrial interage com a comunidade, tendo em vista que esta a contém em três fases distintas: quando recebe fatores de produção; quando os processa; quando expede produtos, resíduos, etc.

Na primeira fase, o efeito predominante dessa interação é o urbanístico; na segunda, o ambiental e na terceira, novamente o urbanístico. Como efeitos urbanísticos podemos citar a concentração populacional, a demanda de tráfego, a alteração da paisagem, e como efeitos ambientais as poluições do solo, água, ar, ruídos, vibrações.

No início do processo de industrialização, a indústria era sinônimo de riqueza, de status. As atividades dispersas e de pequena dimensão pouco demandavam em termos de infra-estrutura urbana; e a capacidade de autodepuração da natureza absorvia os efeitos ambientais gerados pelas atividades. Não havia, portanto, grande concentração de poluentes, o que veio ocorrer, posteriormente, em função do aglomerado urbano e industrial, fazendo com que as transformações sociais passassem a identificar a indústria como algo opressor, sujo, inconveniente. Essa ressonância não foi devidamente prevista e cuidada pelo poder público, caminhando-se, então, rapidamente, para o esgotamento de fatores de produção, considerados anteriormente como inexauriveis, tais como: os recursos naturais, a energia, a infra-estrutura urbana.
Não havia paralelismo entre o incentivo à localização industrial e a geração de infra-estrutura, capaz de absorver o impacto dessa atividade, também geradora de concentração urbana. E surgia, portanto, a poluição em todas as suas formas e com toda a sua ênfase, multiplicada pelas insatisfações sociais.

A poluição se identifica, portanto, com a exaustão do recurso natural; e a atividade industrial, concentrando demanda do recurso, ressalta esse efeito.

Houvesse o poder público previsto o ajuste disponibilidade/demanda do recurso água/solo/ar e induzido o processo de ocupação do solo em função desse ajuste não estaríamos hoje frente a uma situação crítica que se necessita corrigir.

Guardadas as devidas proporções, o fenômeno poluição mostra certo paralelismo com a crise energética gerada pela imprevisão com relação à disponibilidade do petróleo.

Os problemas específicos de poluição, energia, urbanismo e assentamento industrial não são os mesmos em todos os lugares, nem tem a mesma gravidade. Enão poderíamos dizer que a essência destes problemas é a falta de recursos, mas sim a falta de organização e, portanto, de administração.

A partir da segunda metade deste século, nosso país vem se transformando radicalmente como conseqüência de dois fenômenos intimamente relacionados: uma desconcertante taxa de crescimento populacional e seu resultante fenômeno de urba- 
nização, desorganizado e caótico, por razões de subdesenvolvimento de um lado e falta de planejamento de outro.

Em função do subdesenvolvimento temos sido incapazes de gerar os recursos econômicos necessários e nossa urbanização está acontecendo antes que a estrutura econômica esteja pronta para enfrentá-la. Necessitar-se-á, portanto, nas próximas décadas, um esforço enorme para descentralizar a população e as atividades econômicas e, conseqüentemente, diminuir os desequilíbrios regionais.

Quando falamos de administração e de qualidade de vida, em verdade estamos estudando os problemas de desenvolvimento, e o aspecto que assinalamos é que estamos administrando mal nossas regiões, por vezes seguindo experiências de outras regiões, imaginando, com isso, poder economizar tempo nesse empreendimento.

Parece-nos que para os problemas de desenvolvimento econômico, controle ambiental, crescimento populacional e urbanização, não existem precedentes históricos e nem modelos que copiar, visto que eles se entrelaçam.

O propósito do Estado não é somente o desenvolvimento e a segurança nacional, mas especialmente a tentativa de harmonizar o crescimento e o desenvolvimento com a melhoria da qualidade de vida. A chamada crise urbana é universal, porém, é bem mais acentuada em paises em desenvolvimento, onde o movimento migratório, devido ao fascínio exercido pelos grandes centros, tem sido impossivel de controlar, prova disto é que nossos centros urbanos estão à beira de um colapso e dificilmente pode-se dizer que existe uma cidade capaz de fornecer a seus habitantes os serviços básicos. E a industrialização, como tendência futura, não será capaz de fornecer emprego a toda essa gente que se aglomera nos grandes centros, considerando-se que a estrutura da indústria está mudando muito rapidamente e que as modernas fábricas procuram cada vez mais máquinas e equipamentos que substituam a mão-de-obra; é a indústria de capital intensivo.

Angustiados por esse verdadeiro impasse de crescimento inexorável da população e a impossibilidade de gerar recursos e empregos é que devem os administradores desenvolver uma atividade meIhor planejada, principalmente em decorrência da escassez de recursos e a recessão.

Para atingir o objetivo de melhoria de qualidade de vida, com a compatibilização do crescimento urbano e industrial, parece-nos fundamental uma ação coordenada e integrada dos níveis federal, estadual e municipal, bem entrosados com a iniciativa privada, para o planejamento e execução de ati- vidades, que permita uma avaliação de seu impacto econômico e social.

Há necessidade de conciliar o resguardo do bem-estar da população com o controle progressivo e racional das situações existentes, de modo a não desorganizar as atividades produtivas nem causar intranquilidade social.

\section{Influências sobre o meio ambiente da indústria de celulose e papel}

A fabricação de celulose e papel pode afetar o meio ambiente de várias maneiras, entre as quais, poder-se-ia citar, descargas de poluentes na atmosfera e em corpos líquidos, geração de ruídos, e até mesmo dizer que suas chaminés e edifícios afetam a paisagem.

Podemos genericamente dividir os efeitos da utilização da celulose e papel sobre o meio ambiente em: derrubada de florestas e implantação de florestas homogêneas; processos de fabricação de papel e celulose; utilização e disposição final dos produtos de papel; perturbações no ecossistema.

As matérias-primas fibrosas, passiveis de utilização na indústria de celulose e papel, possuem, em regra, menos de $50 \%$ de celulose, o restante é constituído de lignina, hemicelulose, açúcares, álcoois, ácidos orgânicos, sais inorgânicos, etc. - , cuja reciclagem e reuso é parcial.

Além disso, existem perdas de reagentes químicos processuais e auxiliares que, também, não são inteiramente reciclados ou reutilizados, encontrandose, desta maneira, nos efluentes líquidos ou nas emissões atmosféricas, a presença de tais reagentes.

Finalménte, pode ocorrer, através de descargas temporárias ou acidentais, perdas de fibras de celulose.

A tecnologia atual tem demonstrado que os diferentes materiais existentes nos efluentes líquidos ou nas emissões atmosféricas possuem um certo valor que não pode ser descartado. Por esse motivo têm sido desenvolvidas técnicas para aumentar o grau de reciclagem das matérias-primas, assim como vem sendo realizadas pesquisas visando descobrir novos e não-convencionais usos dos subprodutos.

Em paralelo com este interesse econômico há uma crescente conscientização sobre a necessidade de se proteger e preservar o meio ambiente. Nesse aspecto, a mentalidade hoje predominante na indústria de celulose e papel mostra ser perfeitamente possivel obter-se uma economia relativa, e, ao mesmo tempo, proteger-se o meio ambiente através de uma minimização das descargas dos resíduos. 
O Brasil tem seu território submetido em sua quase totalidade a um regime tropical, sofrendo, por esse motivo, os efeitos de alta pluviosidade e forte insolação. Como conseqüência disso a presença de maciços florestais impede a formação de regime torrencial enquanto solos desprotegidos de vegetação sofre mecanismos de erosão acelerada. Dessa maneira o manejo do revestimento florestal é de suma importância para a conservação dos solos e das águas. Há crescente demanda de produtos florestais ocasionada por crescimento acelerado do mercado externo e interno, além de constituir-se, a madeira, prioridade primeira para substituição de combustíveis derivados de petróleo em alguns setores industriais; daí a necessidade de um planejamento objetivando uma exploração racional e adequada, de maneira a permitir o progresso em harmonia com a natureza.

\section{Poluentes atmosféricos}

O dióxido de enxofre, emitido principalmente por fábricas de celulose Kraft e fábricas de sulfito, é oxidado na atmosfera, e o trióxido de enxofre, assim formado, e lavado pelas chuvas, cai na forma de ácido sulfúrico. Este acidifica tanto a terra como a água modificando a vida biológica e acelerando a corrosão.

Os compostos mal-odorosos presentes, por exemplo, nas emissões de processos de cozimento de sulfato são constituídos principalmente de sulfeto de hidrogênio e sulfetos orgânicos. Tais gases apresentam um difícil problema de poluição e, para tanto, tem-se projetado vários sistemas com o objetivo de reduzir seus efeitos sobre o meio ambiente.

Os compostos clorados são emitidos em menores quantidades, principalmente nos processos de branqueamento e são do tipo difuso, ou seja, não se localizam em algum ponto particular.

As poeiras inorgânicas, constituídas principalmente de carbonatos e sulfatos, além de representarem perdas processuais, aumentam a corrosão de equipamentos e provocam efeitos no meio ambiente por diminuírem a transmissibilidade da luz solar incidente, quando em suspensão no ar.

\section{Poluentes líquidos}

Podem ser classificados em: sólidos suspensos; compostos lentamente biodegradáveis; compostos facilmente biodegradáveis; compostos tóxicos; compostos que alteram o $\mathrm{pH}$; íons inorgânicos; resíduos de reagentes químicos auxiliares.

Os sólidos suspensos, presentes nos efluentes das indústrias de papel e celulose, constituemse principalmente de fibras ou partículas fibrosas. Es- se material tende a sedimentar-se em áreas vizinhas ao ponto de descarga, formando leito de fibras onde pode ocorrer uma decomposição biológica com a conseqüente formação de gás metano.

Fibras finas em suspensão que não sedimentam causam no corpo receptor aumento de turbidez da água e redução de sua transmitância à luz; sintomas de asfixiamento em peixes, influência em seu crescimento e alteração de sua composição sanguínea, etc.

Os teores de compostos facilmente biodegradáveis são mensurados através de demanda bioquímica de oxigênio - DBO, que constitui na quantidade de oxigênio consumida na oxidação bioquímica de matéria orgânica, em determinadas condições. Uma considerável parte dos componentes da madeira dissolvidos na água é facilmente biodegradável.

Exemplos de tais compostos são hemicelulose de baixo peso molecular, ácido acético, ácido fórmico, açúcares, etc. A ação deletéria destes compostos ocorre porque a absorção do oxigênio contido nas águas receptoras afetam as espécies biológicas, porventura existentes, ocorrendo conseqüentemente um processo de fermentação.

Os compostos de biodegradação lenta são constituídos principalmente de substâncias de alto peso molecular (lignina e carboidrato), podendo sua presença ser estimada pela medida do teor da demanda química de oxigênio - DQO, que representa a quantidade total de substâncias oxidáveis presentes. Tais compostos, geralmente, são coloridos e, portanto, influenciam a penetração de luz na água e a qualidade da água potável. Aqueles que possuem uma tendência à absorção por organismos vivos podem acumular-se e causar efeitos biológicos.

Os efeitos tóxicos dos efluentes de fábricas de celulose têm sido intensivamente estudados e as pesquisas sobre toxidade dos efluentes das várias etapas de uma fábrica kraft mostram que o licor negro e depois os condensados contêm os componentes mais tóxicos para os peixes. Os estágios de cloração e alcalino na etapa de branqueamento freqüentemente produzem efluentes com substâncias tóxicas.

Os efluentes das fábricas de celulose podem afetar, também, o $\mathrm{pH}$ dos corpos receptores, podendo-se verificar que, geralmente, os altos valores ( $\mathrm{pH}$ maior que 9) como os baixos ( $\mathrm{pH}$ menor que 5) influenciam a vida biológica e aumentam o efeito tóxico dos efluentes.

Sais inorgânicos dissolvidos normalmente não causam danos à vida aquática, entretanto, sais contendo nitrogênio e fósforo atuam como fertilizantes 
nos receptores, contribuindo para aumentar a velocidade de eutrofização.

É extremamente difícil avaliar-se o impacto global no meio ambiente causado pelos resíduos das indústrias de papel e celulose. Deve-se ter em mente, porém, que nehum poluente age por si próprio, e sim como parte de um complexo constituído por outros agentes físicos ou químicos, onde o efeito final é o resultado de muitos fatores atuando juntos. A natureza de tais interações ainda não é totalmente conhecida, sendo que a primeira condição para prever-se o impacto ambiental é conhecer como os resíduos se distribuem no sistema e similarmente ter um conhecimento da distribuição após um determinado tempo. Além disso, é necessário conhecer a ta$x a$ do metabolismo dos poluentes por microorganismos e animais. Os resíduos da fabricação de celulose e papel contêm uma ampla variedade de compostos com diferentes pesos moleculares e várias características e as espécies químicas que ocorrem nesta mistura complexa não somente são indefinidas até o momento como também difíceis de definir devido a sua alta reatividade, ou seja, a contínua transformação de compostos.

Numa tentativa de se criar uma base comum para avaliar as diferentes influências, dois critérios básicos são sugeridos para classificação: extensão do efeito no tempo e extensão do efeito no espaço.

Neste contexto, deve-se ter em mente que um "efeito ecológico" é definido como um desequilíbrio do ecossistema. A "seriedade" de um efeito é julgada através do tempo necessário, a partir do momento em que ocorreu o distúrbio, até a restauração do equilíbrio original.

A distribuição espacial dos efeitos é também importante, pois se ocorrem efeitos ambientais numa vasta área, estes, são considerados mais sérios do que aqueles que afetam uma pequena área.

Dentro desses conceitos as perturbações ambientais serão subdivididas em efeitos a curto e a longo prazos.

No primeiro caso estão os efeitos que causam distúrbios rapidamente reversíveis nos ecossistemas, e às vezes, podem não ser os causadores dos efeitos ecológicos mais adversos, contudo, são normalmente bastante drásticos (por exemplo: morte de peixes), sendo, portanto, os que têm recebido maior atenção do público. Esta é talvez a principal razão por que a maior parte dos estudos de poluição tem se concentrado na eliminação dos efeitos a curto prazo. No segundo caso tem-se aqueles efeitos que causam perturbações irreversíveis no equilíbrio do ecossistema, por isso, todos os estudos relacionados com poluição deveriam dar prioridade à redu- ção ou eliminação de substâncias que causam tais efeitos.

A maioria dos estudos quanto a efeitos causados em plantas e animais pelos efluentes da indústria de papel e celulose, foram realizados no Canadá, EUA e nos Países Escandinavos. Conseqüentemente, em outras partes do mundo existe pouco conhecimento com relação a tais efeitos, principalmente sobre os corpos receptores: Quase nada é conhecido acerca dos efeitos ecológicos em águas nas áreas tropicais e subtropicais, portanto, há necessidade de se orientar pesquisas nestas áreas, de maneira a obter-se dados confiáveis e não baseados nos alienígenas, visando uma melhor compreensão dos efeitos ecológicos que se vem verificando.

\section{Esforços conjuntos das empresas de celulose e papel da ANFPC, e da Cetesb para equacionamento da poluição ambiental.}

Atualmente, observa-se grande esforço por parte da indústria de papel e celulose em reduzir o impacto dos efluentes poluidores, através de modificações no processo de fabricação e na implantação de sistemas de tratamento. Para a minimização do quadro apresentado anteriormente a Companhia de Tecnologia de Saneamento Ambiental - Cetesb, através de trabalhos já executados, acumulou conhecimento específico, visando não apenas o controle da poluição hídrica e atmosférica, mas a conciliação desta atividade com o desenvolvimento do in plant control, objetivando a diminuição das perdas, obtenção de produtos rentáveis, recirculação das águas e controle do processo produtivo. Em conseqüência destas atividades há a redução de investimentos na construção de sistemas de tratamento acompanhada de minimização de custos operacionais.

Especificamente com relação à poluição atmosférica, a Associação Nacional dos Fabricantes de Papel e Celulose - ANFPC solicitou solaboração da Cetesb, com o objetivo de executar estudos para redução dos odores produzidos, levando-se em consideração padrões de emissão e efeitos no ambiente.

Em síntese, são os seguintes os estudos que vêm sendo realizados conjuntamente pela Cetesb e ANFPC, objetivando a solução dos problemas de poluição ambiental:

- avaliação ecológica e ecotoxicológica dos corpos de água receptores, através de coletas e análises de parâmetros físicos, químicos e biológicos. São também realizados bioensaios com águas industriais e do corpo receptor, utilizando-se de organismos aquáticos nestes testes, objetivando verifi- 
car o nível de toxidez na ecologia aquática e na utilização das águas. Medidas de descargas são realizadas a montante e a juzante dos pontos de emissão industrial;

- levantamento industrial, cuja função principal é verificar as etapas do processo produtivo, caracterização qualitativa e quantitativa dos despejos, fornecendo dados significativos no desenvolvimento de experiências de tratabilidade de laboratório e piloto.

Estes estudos têm permitido implantação de sistemas de tratamento que, segundo experiências da Cetesb, podem ser realizados de várias maneiras, através de sistemas de recuperação, sedimentação e flotação para remoção de materiais suspensos; precipitação química para remoção de cor; processos biológicos; lagoas de estabilização para degradação da matéria orgânica; lagoas aeradas, lodos ativados, etc.

Há muitas idéias falsas a respeito da poluição do meio ambiente provocada pelas atividades industriais; com relação à poluição hídrica muitos pensam que as indústrias são as principais fontes de poluição industrial. Isto pode decorrer de dois aspectos inerentes à poluição industrial:

- ela é casuística e facilmente identificável;

- freqüentemente ela é espetacular, por algumas características dos efluentes, tais como, a cor, a temperatura, a presença de espumas, etc.

$\mathrm{Na}$ realidade, a maior fonte de poluentes no Brasil de nossos dias está nos campos: são as atividades agropecuárias que correspondem a uma po- pulação equivalente a mais de quinhentos milhões de habitantes; em segundo lugar está a população doméstica com mais de cem milhões de habitantes $\mathrm{e}$, finalmente, vem o nosso parque industrial que, excetuando as indústrias de natureza agroindustrial, equivalem a pouco mais de sessenta milhões de habitantes.

Desta forma, parece-nos absolutamente sensata e coerente a atitude dos empresários do setor de celulose e papel em procurar desmistificar certas afirmações que envolvem e comprometem a imagem deste, que se identifica como um dos mais potenciais setores do parque industrial brasileiro.

Dentre esses mitos, citamos a errônea conceituação de que a floresta homogênea seja responsável por danos irreparáveis no solo, flora e fauna. Estudos desenvolvidos pelo professor Heládio do Amaral Melo, da Escola Superior de Agricultura Luiz de Queiroz - ESALQ, através de trabalho realizado pelo Instituto de Pesquisa e Estudos Florestais - IPEF, comprovam que a reposição florestal do eucalipto é do mesmo nível do pertencente à Floresta Amazônica, e florestamentos realizados indicam aumento do número de animais existentes na floresta. 0 mesmo se diga com relação à poluição em qualquer de suas formas, eis que os trabalhos anteriormente citados indicam que o problema já está perfeitamente diagnosticado, e se soluções de maior amplitude não foram conseguidas, isto deve-se ao próprio gradualismo assumido pelos governos estaduais e federal para a condução deste assunto, além das naturais dificuldades de noviciado brasileiro nessa matéria. 
.

$+$

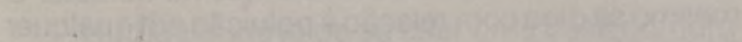

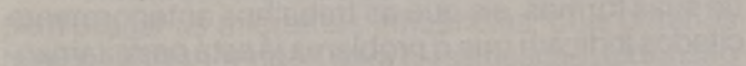

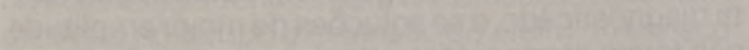

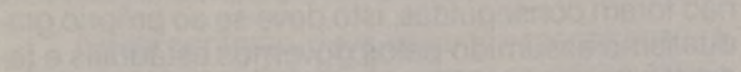

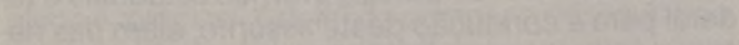
. 